\title{
Hyperglycemia in pregnancy: sleep alterations, comorbidities and pharmacotherapy
}

\author{
Cristina Façanha ${ }^{1 *}$ (D), Veralice de Bruin² (1), Pedro de Bruin² (D), Arthur Façanha ${ }^{3}$ (D), \\ Hellen Cristina Rocha ${ }^{3}$ (D), Mariana Araujo ${ }^{4}$ (1), Adriana Forti ${ }^{5}$ (1), Rejane Macêdo ${ }^{5}$ (1)
}

\section{SUMMARY}

OBJECTIVE: To investigate sleep alterations and associated factors in pregnant diabetic women $(n=141)$.

METHODS: Sleep profile, sociodemographics and clinical information were collected. Poor sleep quality (Pittsburgh Sleep Quality Index $>5$ ) and excessive daytime sleepiness (Epworth Sleepiness Scale $\geq 10$ ), sleep duration (h), sleep latency (min), frequent sleep interruption and short sleep ( $\leq 6 \mathrm{~h}$ ) were assessed in type 1 diabetes mellitus (16.3\%), type 2 diabetes mellitus (25.5\%) and gestational diabetes mellitus (58.2\%).

RESULTS: Poor sleep quality was found in $58.8 \%$ of patients and daytime sleepiness in $25.7 \%$, regardless of hyperglycemia etiology. No correlation existed between daytime sleepiness and poor sleep quality (Pearson correlation $r=0.02, p=0.84$ ). Short sleep duration occurred in $1 / 3$ of patients (31.2\%). Sleep interruptions due to frequent urination affected $72 \%$ of all and sleep interruptions due to any cause $71.2 \%$. Metformin was used by $65.7 \%$ of type 2 diabetes mellitus and $28.7 \%$ of gestational diabetes mellitus. In gestational diabetes mellitus, parity number was independently associated with poor sleep quality $(p=0.02 ; O R=1.90 ; 95 \% \mathrm{Cl} 1.07-3.36)$ and metformin use was also independently associated with poor sleep quality ( $p=0.03$; OR=2.36; 95\% Cl 1.05-5.29).

CONCLUSIONS: Our study originally shows that poor sleep quality and excessive daytime sleepiness are frequent in diabetic pregnancy due to different etiologies. Interestingly, only in gestational diabetes mellitus, metformin therapy and higher parity were associated with poor sleep quality.

KEYWORDS: Diabetes mellitus. Sleep. Pregnancy in diabetics. Diabetes, gestational. Sleepiness.

\section{INTRODUCTION}

Hyperglycemia complicates nearly 1/5 of pregnancies and may be secondary to type 1 (T1DM) and type 2 diabetes (T2DM), or gestational diabetes mellitus (GDM) ${ }^{1}$. Diagnosing and providing care to women with hyperglycemia in pregnancy should be a priority, given that diabetes during gestation is associated with adverse maternal and neonatal outcomes ${ }^{2}$.

Sleep alterations are also frequent in pregnancy and poor sleep quality is reported in about $45.7 \%$ of pregnant women ${ }^{3}$.
Short sleep, excessive daytime somnolence and poor sleep quality due to different etiologies has also been related to adverse pregnancy outcomes, such as preterm birth, Cesarean delivery, gestational diabetes and pre-eclampsia ${ }^{4,5}$.

There is compelling evidence that sleep alterations are linked to metabolic disorders and cardiovascular disease. Short sleep duration, sleep quality and, recently, long sleep duration have all been linked to poor health outcomes ${ }^{6}$. Both short and long sleep duration are associated with increased risk of T2DM,

\footnotetext{
'Universidade Federal do Ceará, Centro Universitário Christus, Centro Integrado de Diabetes e Hipertensão do Ceará - Fortaleza (CE), Brasil. ¿Universidade Federal do Ceará - Fortaleza (CE), Brasil.

${ }^{3}$ Centro Universitário Christus - Fortaleza (CE), Brasil.

${ }^{4}$ Universidade Federal do Ceará, Centro Universitário Christus - Fortaleza (CE), Brasil.

${ }^{5}$ Universidade Federal do Ceará, Centro Integrado de Diabetes e Hipertensão do Ceará - Fortaleza (CE), Brasil.

*Corresponding author: crisffacanha@hotmail.com

Conflicts of interest: the authors declare there is no conflicts of interest. Funding: none.

Received on August 18, 2020. Accepted on August 19, 2020.
} 
strengthening the significance of appropriate sleep duration in the prevention and management of $\mathrm{T}_{2} \mathrm{DM}^{7}$. Obstructive sleep apnea (OSA), a frequent cause of sleep disruption, is associated with increased incidence of T2DM in large cohort studies, and also related to high glycated hemoglobin (Hbalc) in patients with $\mathrm{T}_{2} \mathrm{DM}^{8}$. The pathophysiological mechanisms explaining the elevated prevalence and significant associations between sleep disorders, increased mortality and comorbid conditions requires more clarification?.

Little is known about sleep in T1DM and even less knowledge exists on sleep in pregnancy associated with T1DM. Poor sleep quality, shorter sleep duration, and OSA were all associated with suboptimal glycemic control in $\mathrm{T}^{1} \mathrm{DM}^{10}$. It has been suggested that the interactions between sleep and type 1 diabetes are bidirectional, as painful peripheral neuropathy, nocturia related to poor glycemic control and hypoglycemic episodes may compromise sleep quality. However, it remains to be clarified whether improvement of sleep favors glycemic control ${ }^{10}$.

Extensive evidence shows an independent association of sleep disturbances with the development, control, and progression of disorders affecting glucose metabolism ${ }^{9}$. In short, sleep is a critical factor in glucose metabolism. Given the ascending prevalence of obesity and T2DM, the importance of lifestyle factors, including dietary intake, exercise, sedentariness, sleep, and stress in the prevention and control of hyperglycemia in pregnancy cannot be understated ${ }^{11}$. Sleep duration is a potential modifiable risk factor, and can be focused upon in order to improve health and pregnancy ${ }^{8}$.

Sleep disturbances have been connected with GDM. Poor sleep quality during early pregnancy was formerly associated with an increased risk of $\mathrm{GDM}^{12}$. Objective measurements support that short sleep duration is linked to maternal hyperglycemia ${ }^{13}$. In partial contradiction, a meta-analysis including 18,203 subjects at baseline, and 1,294 GDM cases during follow-up, showed that extreme sleep duration during pregnancy is closely associated with GDM: long but not short sleep duration would predict the risk of developing $\mathrm{GDM}^{14}$.

This conflicting data indicates that undetermined factors may influence sleep and add to the toxicity of hyperglycemia in pregnancy. Basic diagnosis, clinical characteristics, comorbidities and pharmacotherapy may influence general health and sleep in pregnancy. For instance, it has been demonstrated that factors such as maternal pregestational body mass index (BMI) and glycemic levels can alter placental mitochondria ${ }^{15}$. Questions remain regarding definition of the glucose threshold for diagnosis of diabetes in pregnancy and recommended pharmacotherapy ${ }^{16}$. Previous study suggests that factors influencing sleep in diabetes associated with pregnancy need to be better understood ${ }^{17}$.

The objective of this study was to examine sleep quality and somnolence, and the influence of associated factors, such as comorbidities and pharmacotherapy, in patients with hyperglycemia, secondary to T1DM, T2DM or GDM, in the $2^{\text {nd }}$ and $3^{\text {rd }}$ trimesters of pregnancy.

\section{METHODS}

\section{Study design, sample and setting}

This was a cross-sectional study conducted at the Center for Diabetes and Hypertension (CIDH-CE) in Northeast Brazil. The unit serves approximately 600 pregnant women with diabetes per year. The study population was derived as a nonprobability sampling, recruiting over a 15-month period, from October 2016 to January 2018. Women with singleton pregnancy, 18 years of age or older, diagnosed with diabetes (T1DM, T2DM, GDM) according to the criteria used by Brazilian Diabetes Society $-\mathrm{SBD}^{18}$ were included. The study was approved by the Insituto para o Desenvolvimento da Educaçáo (IPADE) ethics committee (1.801.860). The objectives and study procedures were explained and a written informed consent was obtained from all patients.

\section{Data collection}

Data was obtained using a face-to-face interview, done by previously trained paramedical professionals. Sleep profile, sociodemographics and clinical information were collected using a structured questionnaire. Information about maternal and gestational age, parity and previous history of sleep disturbances were obtained from patient interview and further confirmed by chart review. Body mass index, blood pressure and information about patients' treatments were collected from their records. During three consecutive days prior to the interview, the information about capillary fasting blood glucose was collected from patients' records and expressed as mean fasting glucose.

For the evaluation of sleep quality, a Brazilian version of the Pittsburgh Sleep Quality Index (PSQI) was used ${ }^{19}$. This instrument consists of seven components: subjective sleep quality, sleep latency, sleep duration, habitual sleep efficiency, sleep disturbances, use of sleeping medication, and daytime dysfunction. The sum of the index scores range from $0-21$, and a score greater than 5 indicates poor sleep quality ${ }^{20}$. Additionally, patients were asked about the average sleep duration (h) and sleep latency ( $\mathrm{min}$ ) in the last 30 days; sleep latency was defined as the time between going to bed and 
falling asleep. Patients were asked whether they had frequent sleep interruption and if it was associated with urination. Short sleep was considered in participants who reported an average sleep duration $\leq 6$ hours per night in accordance with recommendations of the National Sleep Foundation, USA ${ }^{21}$. The validated Brazilian version of the Epworth Sleepiness Scale (ESS) was used to assess the level of daytime sleepiness ${ }^{19}$. ESS scores ranged from 0-24. Excessive daytime sleepiness (EDS) was defined as a total score $\geq 10^{22}$.

\section{Statistical analysis}

Descriptive statistics are presented as mean \pm standard deviation, range, and frequency (\% values). Analysis between groups were made using Kruskal-Wallis or one-way analysis of varience (ANOVA), followed by Mann-Whitney or Student's t-test, when appropriate. Pearson correlation test was used between PSQI and ESS scores. The selection of variables analyzed for association with poor quality sleep and EDS were based on previous reports, clinical impression, and data that was obtained. Variables associated with poor sleep quality were examined by logistic regression analysis.

\section{RESULTS}

Initially, a total of 165 patients agreed to participate in the study. Out of these, 24 were excluded: 23 failed to provide complete data and 1 was out of age range. Finally, the total number of study participants came to 141 pregnant diabetic women. Diabetes before pregnancy was present in $41.8 \%: 16.3 \%$ had T1DM and 25.5\% T2DM. The remaining 58.2\% developed diabetes mellitus during pregnancy (GDM). T1DM patients were younger, had lower BMI and were evaluated in a lower gestational age. Patients with GDM had more remunerated work. Pharmacological treatment, i.e. metformin or insulin, was used by all the preexistent diabetic patients (T1DM and T2DM). Patients with T2DM (65.7\%) and with GDM (28.7\%) used metformin. Levels of fasting blood glucose and insulin dose were higher in T1DM and T2DM than in GDM. Metformin was more frequently used in T2DM than in GDM (Table 1). The association of metformin and insulin was also more common in T2DM than in GDM.

Regardless of diabetes etiology, poor sleep quality ${ }^{20}$ was observed in $58.8 \%$ of patients. Overall, $16 \%$ of the study group reported subjective sleep complaints before pregnancy. In general, PSQI

Table 1. Clinicodemographic data of all pregnant women and as grouped by diagnosis - Type 1 diabetes mellitus, Type 2 diabetes mellitus and Gestational diabetes mellitus.

\begin{tabular}{|c|c|c|c|c|c|}
\hline & $\begin{array}{l}\text { All patients } \\
\quad \mathrm{n}=141\end{array}$ & $\begin{array}{c}\text { Type } 1 \\
\text { diabetes } \\
\text { mellitus } n=23 \\
(16.3 \%)\end{array}$ & $\begin{array}{c}\text { Type } 2 \\
\text { diabetes } \\
\text { mellitus } \mathrm{n}=36 \\
(25.5 \%)\end{array}$ & $\begin{array}{c}\text { Gestational } \\
\text { diabetes } \\
\text { mellitus } n=82 \\
(58.2 \%)\end{array}$ & p-value \\
\hline \multicolumn{6}{|l|}{ Clinical Profile } \\
\hline Age, years mean (SD) & $31.6(5.8)$ & $25.2(4.6)$ & $34.0(4.9)$ & $32.6(5.2)$ & ${ }^{\star *}<0.01^{a}$ \\
\hline Body mass index $\left(\mathrm{kg} / \mathrm{m}^{2}\right)$ mean $(\mathrm{SD})$ & $30.7(5.4)$ & $26.2(4.25)$ & $30.9(4.6)$ & $31.9(5.4)$ & $* *<0.01^{a}$ \\
\hline Glycemia (mg/dL) mean (SD) & $88.9(11.0)$ & 98.5 & 90.1 & 83.9 & $* *<0.005$ \\
\hline Gestational age (weeks) mean (SD) & $25.0(8.1)$ & $19.8(7.2)$ & $21.5(8.1)$ & 28.(6.9) & ${ }^{*}<0.01^{\mathrm{a}}$ \\
\hline Parity $(n)$ mean $(S D)$ & $1.24(1.0)$ & $1.0(0.8)$ & $1.3(1.0)$ & $1.28(1.1)$ & $0.50^{\mathrm{a}}$ \\
\hline Abortion (n) mean (SD) & $0.48(1.0)$ & $0.25(0.5)$ & $0.67(0.8)$ & $0.46(0.7)$ & $0.12^{\mathrm{a}}$ \\
\hline Remunerated work (\%) & 50.8 & 47.8 & 28.1 & 58.7 & $0.01^{c}$ \\
\hline Any pharmacological treatment (\%) & 62.6 & 100 & 100 & 35 & ${ }^{* *}<0.005^{c}$ \\
\hline Metformin mean (mg/day) (SD) & $1.62(0.43)$ & - & $1.8(0.36)$ & $1.35(0.41)$ & $* *<0.01$ \\
\hline Insulin (UI/kg) mean (SD) & $0.62(0.34)$ & $0.94(0.28)$ & $0.51(0.27)$ & $0.28(0.14)$ & $* *<0.005$ \\
\hline Hypertension (\%) & 20 & 4.5 & 22.9 & 23.1 & $0.13^{c}$ \\
\hline Overweight/obesity (\%) & 77.1 & 45.5 & 91.2 & 79.7 & $* *<0.005^{c}$ \\
\hline \multicolumn{6}{|l|}{ Sleep Profile } \\
\hline $\begin{array}{l}\text { Pittsburgh Sleep Quality Index Score } \\
(\text { mean } \pm \text { SD) }\end{array}$ & $6.7 \pm 3.4$ & $5.9(2.7)$ & $6.6(3.4)$ & $7.3(3.5)$ & $0.35^{b}$ \\
\hline Epworth Score $($ mean $\pm S D)$ & $6.9 \pm 3.9$ & $6.9 \pm 3.9$ & $6.5(4.2)$ & $7.19(4.0)$ & $0.52^{b}$ \\
\hline Sleep Duration, h (mean \pm SD) & $7.3 \pm 1.7$ & $7.22 \pm 1.5$ & $7.0(1.5)$ & $7.46(1.9)$ & $0.43^{a}$ \\
\hline Sleep interruption (\%) & 71.2 & 73.9 & 86.1 & 63.8 & $0.05^{c}$ \\
\hline
\end{tabular}

SD: standard deviation; Overweight/obesity: body mass index adjusted for gestational; ${ }^{\text {Annova; }}{ }^{\text {KK}}$ Kruskall-Wallis test; ${ }^{\text {c }}$ isher's exact test; * $\mathrm{p}<0.05 ;{ }^{* *} \mathrm{p}<0.01$. 
mean score was 6.8. Patients with GDM tended to have higher scores (mean=7.03, DP $=3.5$ ) than the other groups (T2DM; mean=6.61, DP=3.4 and T1DM; mean=5.87, DP=2.7); however, this difference was nonsignificant (Kruskal-Wallis, $\mathrm{p}=0.41$ ) (Table 1). In general, EDS (ESS $\geq 10$ ), was observed in $25.7 \%$. No correlation was found between daytime sleepiness (ESS scores) and sleep quality (PSQI scores) (Pearson correlation test, $r=02, p=84$ ).

Furthermore, short sleep duration ( $\leq 6$ hours) was registered in $31.2 \%$ and sleep latency was 35 minutes on average. Sleep interruptions due to frequent urination occurred in $72 \%$ of all patients. There were no significant differences in sleep quality, sleep duration or EDS among patients with diabetes due to different etiologies. Sleep interruption of any cause (71.2\%) tended to be more frequent in type $2 \mathrm{DM}$ (Fisher's exact test, $\mathrm{p}=0.05$ ) (Table 1 ).

Table 2 exhibits logistic regression analysis between variables and poor sleep quality. After grouping by diagnosis, in GDM patients, parity number was associated with poor sleep quality (Figure 1) that was maintained after controlling for age $(\mathrm{p}=0.02 ; \mathrm{OR}=1.90 ; 95 \% \mathrm{CI} 1.07-3.36]$. Furthermore, in GDM patients, metformin therapy was also associated with poor sleep quality (Figure 2) that was maintained after controlling for age and parity $(\mathrm{p}=0.03 ; \mathrm{OR}=2.36 ; 95 \% \mathrm{CI} 1.05-5.29)$. This was not the case with T2DM (Table 2). Other variables, such as BMI, gestational age, abortion, remunerated work or hypertension did not estimate the presence of poor sleep quality (Table 2).

\section{DISCUSSION}

This study shows that poor sleep quality and ESS are frequent in hyperglycemia in pregnancy, despite the differential etiology. Higher parity was associated with worst sleep quality.

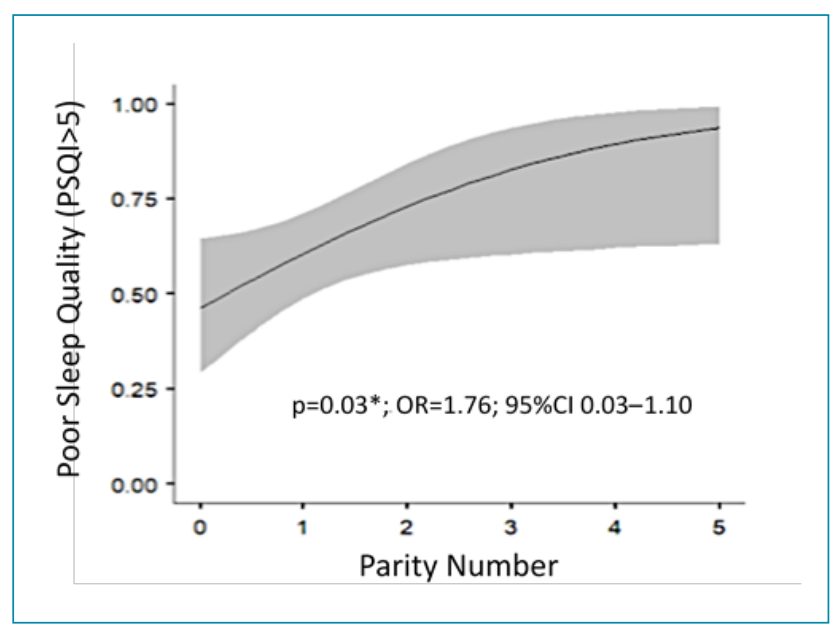

Figure 1. Logistic regression analysis between poor sleep quality and parity number.

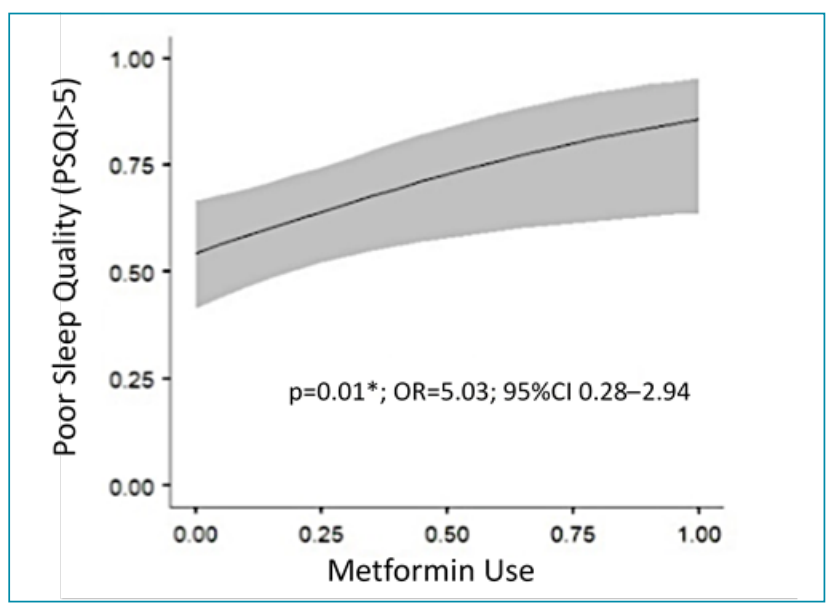

Figure 2. Poor sleep quality and metformin use in gestational diabetes mellitus patients.

Table 2. Logistic regression analysis of factors influencing poor sleep quality (Pittsburgh Sleep Quality Index Score $>5$ ) in patients with Type 1 diabetes mellitus, Type 2 diabetes mellitus and Gestational diabetes mellitus.

\begin{tabular}{|c|c|c|c|}
\hline & Type 1 diabetes mellitus & Type 2 diabetes mellitus & $\begin{array}{c}\text { Gestational diabetes } \\
\text { mellitus }\end{array}$ \\
\hline & p-value; OR [95\%Cl] & p-value; OR [95\%Cl] & p-value; OR [95\%Cl] \\
\hline Age, years & $0.13 ; 0.85[0.69-1.05]$ & $0.66 ; 1.03[0.88-1.21]$ & $0.97 ; 1.00[0.91-1.09]$ \\
\hline Body mass index $\left(\mathrm{kg} / \mathrm{m}^{2}\right)$ & $0.85 ; 1.01[0.83-1.24]$ & $0.32 ; 0.92[0.79-1.07]$ & $0.75 ; 1.01[0.93-1.10]$ \\
\hline Gestational age (weeks) & $0.40 ; 1.05[0.93-1.18]$ & $0.48 ; 0.96[0.87-1.06]$ & $0.32 ; 0.96[0.90-1.03]$ \\
\hline Parity $(n)$ & $1.00 ; 1.00[0.37-2.66]$ & $0.95 ; 0.97[0.49-1.92]$ & $0.03 * ; 1.76[0.03-1.10]$ \\
\hline Abortion (n) & $0.67 ; 0.70[0.13-3.76]$ & $0.69 ; 1.19$ [0.49-2.86] & $0.69 ; 1.14[0.58-2.21]$ \\
\hline Remunerated work (\%) & $0.53 ; 1.68[0.32-8.75]$ & $0.38 ; 0.49[0.10-2.39]$ & $0.66 ; 0.80[0.31-2.11]$ \\
\hline Lives with partner (\%) & $0.46 ; 0.85[0.28-16.3]$ & $1.00 ; 1.30[0.88-1.21]$ & $0.63 ; 1.42[0.33-6.01]$ \\
\hline Metformin (\%) & $0.83 ; 0.91[0.69-1.05]$ & $0.92 ; 0.93[0.88-1.21]$ & $0.01 * ; 5.03[0.28-2.94]$ \\
\hline Hypertension (\%) & $1.00 ; 0.85$ [0.69-1.05] & $0.22 ; 2.77[0.53-14.5]$ & $0.47 ; 0.65[0.20-2.09]$ \\
\hline
\end{tabular}

${ }^{*} \mathrm{p}<0.05$. 
In patients with GDM, the use of metformin was independently associated with poor sleep quality. These results are vital, given that poor sleep is a largely modifiable parameter. Identifying and treating sleep disturbances in pregnancy may positively influence glycemic control, maternal and fetal well-being.

It is recognized that poor sleep quality generally occurs in pregnancy. In literature, studies on poor sleep quality vary from 37 to $66 \%$ according to patients' characteristics and gestational age $^{23}$. A recent meta-analysis reported an estimate mean PSQI score $=6.07,95 \%$ CI $5.30-6.85^{3}$, and an overall prevalence of poor sleep quality (PSQI $\geq 5$ ) in $45.7 \%$ of pregnant women in general. Recently, in a study evaluating healthy pregnant women in a primary care setting in the city of Fortaleza/Brazil, poor sleep quality was found in $42 \%$ (PSQI: $5.6 \pm 3$ ) and EDS in $28 \%$ (ESS: $7.6 \pm 4)^{24}$. In this study, patients with hyperglycemia, in particular patients with GDM and T2DM, had worse sleep quality expressed as higher PSQI scores. Despite the common presence of poor sleep quality in healthy pregnancy, it is recommended that moderate/severe cases are attended to, given the potential maternal and neonatal adverse outcomes.

To date, studies evaluating sleep quality in diabetic pregnancy are scarce, and conflict regarding associated factors and pharmacotherapy still exist. Metformin is a widely used antidiabetic drug to treat insulin resistance. Its use during pregnancy has been increasingly common in daily practice ${ }^{25}$. Besides knowledge of benefits of glycemic control, weight neutral effects and low risk of hypoglycemia, metformin use during pregnancy remains a matter of concern among physicians ${ }^{26}$. Previous evidence regarding the use of metformin and sleep alterations are mixed: metformin has been linked to improvement of sleep quality ${ }^{27}$ and, conversely, was associated with insomnia and nightmares $^{28}$. Presently, only GDM patients had poor sleep quality related to metformin therapy. It has been properly theorized that glucose control substances interfere with brain levels of glucose and lactate, and, as a consequence, an interference with cerebral metabolism and function would occur ${ }^{29}$. We speculate that in some GDM patients, glycemia levels are more borderline, exposing patients to critical levels during sleep. A prospective study focusing on metformin dosage, time of administration, or glucose levels during sleep might be clarifying.

Excessive daytime sleepiness was found in $25.7 \%$ of patients evaluated in this study. Interestingly, sleep quality was not associated with EDS. Using a different cutoff to define EDS (ESS $>8$ ), Reutrakul et al..$^{30}$ reported EDS in $42 \%$ of pregnant women evaluated, and the prevalence was similar in pregnancy with or without diabetes.

In our study, BMI was noninfluential to sleep quality or EDS. Previously, Ribeiro et al. ${ }^{31}$ reported poor sleep quality in $67.7 \%$ of a group of overweight and obese nondiabetic pregnant women in Brazil; PSQI score was higher in overweight/obese patients $(\mathrm{p}=0.02)$. Other reports in pregnancy are similar ${ }^{22,33}$. In fact, high pre-pregnancy $\mathrm{BMI}$ is a critical determinant for sleep disturbances and for the development of gestational diabetes ${ }^{33}$. Considering our results, we hypothesize that diabetes itself is the main contributor to poor sleep quality and, therefore, the differences of sleep quality between thin and overweight pregnant woman were attenuated.

In this study, poor sleep was not associated with hypertension. A relationship between hypertension and sleep in nonpregnant patients has been described, however, during pregnancy, the association between PSQI score and hypertension was not demonstrated ${ }^{34}$.

In GDM patients, parity was independently associated with poor sleep quality. Similar findings have been reported in nondiabetic pregnancy ${ }^{35}$.The additional overload of housework and worries that pregnant mothers are exposed to might influence sleep, and should be taken into consideration when evaluating sleep quality in pregnancy. Nulliparous and multiparous mothers face different challenges during pregnancy and perinatal period, as they incorporate their new role as a mother and the additional demands of previously born children.

Limitations must be acknowledged. This study involved behavioral questionnaires and, as a pitfall, objective measures such as actigraphy and polysomnography were not available. Moreover, investigation of sleep breathing problems, especially in risk groups like overweight and older pregnant women, were not available.

Originally, and as a merit, this study shows the clinical profile and factors influencing sleep alterations in pregnancy associated with hyperglycemia due to different etiologies.

\section{CONCLUSION}

This study shows that poor sleep quality and excessive daytime sleepiness are frequent in diabetic pregnancy. These findings were similar among T1DM, T2DM and GDM. Interestingly, a higher number of parities and metformin treatment were independently associated with poor sleep quality only in GDM patients.

\section{AUTHORS' CONTRIBUTIONS}

CF: Conceptualization, Data Curation, Investigation, Methodology, Writing - Original Draft, Writing - Review and Editing. VB: Conceptualization, Formal Analysis, Methodology, Writing - Original Draft, Writing - Review and Editing. AF: Investigation, Writing - Original Draft, Writing - Review and Editing. MA: Conceptualization, Investigation, Writing - Original Draft, Writing - Review and Editing. AF: Writing - Review and Editing. RM: Investigation, Writing - Review and Editing. HCR: Investigation. PB: Project Administration, Writing - Review and Editing. 


\section{REFERENCES}

1. Goldenberg RL, McClure EM, Harrison MS, Miodovnik M. Diabetes during pregnancy in low- and middle-income countries. Am J Perinatol. 2016;33(13):1227-35. https://doi. org/10.1055/s-0036-1584152

2. Schaefer-Graf U, Napoli A, Nolan CJ; Diabetic Pregnancy Study Group. Diabetes in pregnancy: a new decade of challenges ahead. Diabetologia. 2018;61(5):1012-21. https:// doi.org/10.1007/s00125-018-4545-y

3. Sedov ID, Cameron EE, Madigan S, Tomfohr-Madsen LM. Sleep quality during pregnancy: a meta-analysis. Sleep Med Rev. 2018;38:168-76. https://doi.org/10.1016/j.smrv.2017.06.005

4. Bourjeily G, El Sabbagh R, Sawan P, Raker C, Wang C, Hott B, et al. Epworth sleepiness scale scores and adverse pregnancy outcomes. Sleep Breath. 2013;17(4):1179-86. https://doi. org/10.1007/s11325-013-0820-9

5. Yang Z, Zhu Z, Wang C, Zhang F, Zeng H. Association between adverse perinatal outcomes and sleep disturbances during pregnancy: a systematic review and meta-analysis. J Matern Fetal Neonatal Med. 2020;1-9. https://doi.org/10.1080/147 67058.2020.1711727.

6. Larcher S, Benhamou PY, Pépin JL, Borel AL. Sleep habits and diabetes. Diabetes Metab. 2015;41(4):263-71. https://doi. org/10.1016/j.diabet.2014.12.004

7. Shan Z, Ma H, Xie M, Yan P, Guo Y, Bao W, et al. Sleep duration and risk of type 2 diabetes: a meta-analysis of prospective studies. Diabetes Care. 2015;38(3):529-37. https://doi. org/10.2337/dc14-2073

8. Ogilvie RP, Patel SR. The epidemiology of sleep and diabetes. Curr Diab Rep. 2018;18(10):82. https://doi.org/10.1007/ s11892-018-1055-8

9. Ryan S. Sleep and diabetes. Curr Opin Pulm Med. 2018;24(6):55560. https://doi.org/10.1097/MCP.0000000000000524

10. Reutrakul S, Thakkinstian A, Anothaisintawee T, Chontong $\mathrm{S}$, Borel AL, Perfect MM, et al. Sleep characteristics in type 1 diabetes and associations with glycemic control: systematic review and meta-analysis. Sleep Med. 2016;23:26-45. https:// doi.org/10.1016/j.sleep.2016.03.019

11. Spruijt-Metz D, O'Reilly GA, Cook L, Page KA, Quinn C. Behavioral contributions to the pathogenesis of type 2 diabetes. Curr Diab Rep. 2014;14(4):475. https://doi.org/10.1007/ s11892-014-0475-3

12. Zhong C, Chen R, Zhou X, Xu S, Li Q, Cui W, et al. Poor sleep during early pregnancy increases subsequent risk of gestational diabetes mellitus. Sleep Med. 2018;46:20-5. https://doi.org/10.1016/j.sleep.2018.02.014

13. Reutrakul S, Anothaisintawee T, Herring SJ, Balserak BI, Marc I, Thakkinstian A. Short sleep duration and hyperglycemia in pregnancy: aggregate and individual patient data meta-analysis. Sleep Med Rev. 2018;40:31-42. https://doi.org/10.1016/j. smrv.2017.09.003

14. Xu YH, Shi L, Bao YP, Chen SJ, Shi J, Zhang RL, et al. Association between sleep duration during pregnancy and gestational diabetes mellitus: a meta-analysis. Sleep Med. 2018;52:6774. https://doi.org/10.1016/j.sleep.2018.07.021

15. Mandò C, Anelli GM, Novielli C, Panina-Bordignon P, Massari M, Mazzocco MI, et al. Impact of obesity and hyperglycemia on placental mitochondria. Oxid Med Cell Longev. 2018;2018:2378189. https://doi.org/10.1155/2018/2378189
16. Behboudi-Gandevani S, Amiri M, Bidhendi Yarandi R, Ramezani Tehrani F. The impact of diagnostic criteria for gestational diabetes on its prevalence: a systematic review and metaanalysis. Diabetol Metab Syndr. 2019;11:11. https://doi. org/10.1186/s13098-019-0406-1

17. Zhu B, Shi C, Park CG, Reutrakul S. Sleep quality and gestational diabetes in pregnant women: a systematic review and metaanalysis. Sleep Med. 2020;67:47-55. https://doi.org/10.1016/j. sleep.2019.11.1246

18. Costa e Forti A, Pires AC, Pittito BA, Gerchman F, Oliveira JEP, ZajdenvergL, et al. Diretrizes da Sociedade Brasileira de Diabetes 2019-2020. São Paulo: Editora Clannad; 2019. p. 19-26.

19. Bertolazi AN. Tradução, adaptação cultural e validação de dois instrumentos de avaliação do sono : Escala de Sonolência de Epworth e Índice de Qualidade do Sono de Pittsburgh. [dissertação]. Porto Alegre: Faculdade de Medicina, Universidade Federal do Rio Grande do Sul, 2008.

20. Buysse DJ, Reynolds CF 3rd, Monk TH, Berman SR, Kupfer DJ. The Pittsburgh Sleep Quality Index: a new instrument for psychiatric practice and research. Psychiatry Res. 1989;28(2):193-213. https://doi.org/10.1016/0165-1781(89)90047-4

21. Hirshkowitz M, Whiton K, Albert SM, Alessi C, Bruni O, DonCarlos L, et al. National Sleep Foundation's sleep time duration recommendations: methodology and results summary. Sleep Health. 2015;1(1):40-3. https://doi.org/10.1016/j. sleh.2014.12.010

22. Johns MW. A new method for measuring daytime sleepiness: the Epworth sleepiness scale. Sleep. 1991;14(6):540-5. https:// doi.org/10.1093/sleep/14.6.540

23. Ladyman C, Signal TL. Sleep health in pregnancy: a scoping review. Sleep Med Clin. 2018;13(3):307-33. https://doi. org/10.1016/j.jsmc.2018.04.004

24. Façanha CFS, Cunha ABA, Façanha AS, S ouza FLL, Bruin PFC, Queiroz CB,et al. Sleep in healthy pregnancy:preliminary results. In: Congresso Brasileiro do Sono 2019. Sleep Sci. 2020;13(supl.1):90-1 .

25. Moll U, Landin-Olsson M, Nilsson C, Ursing D, Strevens $H$. Pregnancy outcome in women with gestational diabetes: a longitudinal study of changes in demography and treatment modalities. Acta Obstet Gynecol Scand. 2020;99(3):333-40. https://doi.org/10.1111/aogs.13758

26. Lindsay RS, Loeken MR. Metformin use in pregnancy: promises and uncertainties. Diabetologia. 2017;60(9):1612-9. https:// doi.org/10.1007/s00125-017-4351-y

27. Kajbaf F, Fendri S, Basille-Fantinato A, Diouf M, Rose D, Jounieaux $V$, et al. The relationship between metformin therapy and sleep quantity and quality in patients with type 2 diabetes referred for potential sleep disorders. Diabet Med. 2014;31(5):577-80. https://doi.org/10.1111/dme.12362

28. Yanto TA, Huang I, Kosasih FN, Lugito NPH. Nightmare and abnormal dreams: rare side effects of metformin? Case Rep Endocrinol. 2018;2018:7809305. https://doi. org/10.1155/2018/7809305

29. Xia W, Luo Y, Chen YC, Chen H, Ma J, Yin X. Glucose fluctuations are linked to disrupted brain functional architecture and cognitive impairment. J Alzheimers Dis. 2020;74(2):603-13. https://doi.org/10.3233/JAD-191217 
30. Reutrakul S, Zaidi N, Wroblewski K, Kay HH, Ismail M, Ehrmann DA, et al. Sleep disturbances and their relationship to glucose tolerance in pregnancy. Diabetes Care. 2011;34(11):2454-7. https://doi.org/10.2337/dc11-0780

31. Ribeiro MC, Nakamura MU, Torloni MR, Scanavino MT, Forte $B M$, Mancini PE, et al. Sleep quality in overweight pregnant women. Rev Bras Ginecol Obstet. 2015;37(8):359-65. https:// doi.org/10.1590/SO100-720320150005415

32. Facco FL, Grobman WA, Reid KJ, Parker CB, Hunter SM, Silver $\mathrm{RM}$, et al. Objectively measured short sleep duration and later sleep midpoint in pregnancy are associated with a higher risk of gestational diabetes. Am J Obstet Gynecol. 2017;217(4):447. e1-447.e13. https://doi.org/10.1016/j.ajog.2017.05.066
33. Guinhouya $B C$, Bisson $M$, Dubois $L$, Sériès $F$, Kimoff $J R$, Fraser WD, et al. Body weight status and sleep disturbances during pregnancy: does adherence to gestational weight gain guidelines matter? J Womens Health (Larchmt). 2019;28(4):53543. https://doi.org/10.1089/jwh.2017.6892

34. Sharma SK, Nehra A, Sinha S, Soneja M, Sunesh K, Sreenivas $V$, et al. Sleep disorders in pregnancy and their association with pregnancy outcomes: a prospective observational study. Sleep Breath. 2016;20(1):87-93. https://doi.org/10.1007/ s11325-015-1188-9

35. Christian LM, Carroll JE, Porter K, Hall MH. Sleep quality across pregnancy and postpartum: effects of parity and race. Sleep Health. 2019;5(4):327-34. https://doi.org/10.1016/j. sleh.2019.03.005 